\title{
JBES will Play an Important Role in Global Biodiversity Research and Conservation
}

\section{Ren $\mathrm{Hai}^{*}$}

South China Institute of Botany, Chinese Academy of Sciences, China

More than 90 countries around world agreed to establish Intergovernmental Science-Policy Platform on Biodiversity and Ecosystem Services (IPBES) on April 21, 2012, in Panama. IPBES is equivalent to the field of biodiversity Intergovernmental Panel on Climate Change (IPCC). IPBES is an interface between the scientific community and policymakers to build capacity for and strengthen the use of science in policy making and address gaps in the sciencepolicy interface on biodiversity and ecosystem services. The Platform's objective is to strengthen the science-policy interface for biodiversity and ecosystem services for the conservation and sustainable use of biodiversity, long-term human well-being and sustainable development. OMICS Group Inc. decided to found a new journal - Journal of Biodiversity \& Endangered Species (JBES) in 2012. I think this journal together with other relevant journals will play an important role in promoting global biodiversity research and conservation work.

Due to over-exploitation, habitat loss and fragmentation, environmental degradation and other human disturbance, coupled with the impact of climate change, the global species are disappearing at an unprecedented rate. Fortunately, the "Convention on Biological Diversity" and "Global Strategy on Plant Conservation" and other international conventions and a lot of national biodiversity conservation and restoration plans began to save biodiversity. Of course, researches on biodiversity science or conservation biology have also been made remarkable progress. A number of influential papers and books on biodiversity have been published. However, I still believe that this new journal will serve as a platform for academic exchange and a timely publication of original scientific research. It also will be able to experience in biodiversity conservation, case summary, cataloging and monitoring of biodiversity conservation. This magazine will eventually serve as biodiversity science personnel training and team building platform. I am convinced that this journal will become one of the most influential and important journals in the field of biology through the author - reviewer- editor - reader interactive information and efforts. 